\title{
CRIAÇÃO DE ALGORITMO PARA ANÁLISE DE IMAGENS DE TRINCAS E DA PELOTA QUEIMADA E CORRELAÇÃO DE SEUS PARÂMETROS COM A RESISTÊNCIA FÍSICA DO MATERIAL*
}

\author{
Heidy de Oliveira Simões ${ }^{1}$ \\ Ana Maria Guilherme Bailon ${ }^{1}$ \\ Alaécio Meschiatti2 \\ Raquel Ramos Almeida da Silva ${ }^{3}$ \\ Vinícius Perin Passigatti ${ }^{4}$ \\ Maurício Cota Fonseca ${ }^{5}$
}

\section{Resumo}

Visando entender os impactos causados pela formação de trincas e deformação das pelotas na qualidade física do material, foi desenvolvido um algoritmo que, através de análise automática de imagens, é capaz de medir o tamanho da trinca, sua largura e comprimento, bem como efetuar as medições de tamanho e morfologia da pelota queimada. Foram analisadas pelotas produzidas com minério hidratado (elevado teor de goethita) com 2 perfis térmicos distintos. Os dados obtidos na análise de imagem foram correlacionados com a resistência à compressão das pelotas e evidenciaram o tamanho das trincas denota notória correlação com a sua resistência física. A medição das trincas formadas pela deformação da pelota no leito (denominadas resiliência) permite evidenciar o quanto a pressão no leito de pelotas impacta na qualidade após a queima, bem como indica o ponto ótimo para que não acarretem em perda da resistência. A medição do tamanho das trincas térmicas mostra-se essencial, pois mesmo em perfis mais suaves de queima pode haver a formação de tais trincas, sendo que o tamanho e a abertura da trinca é que definem a melhor ou pior resistência. O conhecimento, e possível aplicação prática, da avaliação das trincas poderá auxiliar na otimização de perfis térmicos de fornos de pelotização.

Palavras-chave: Pelotas; Trincas; Análise automática de imagens.

\section{CREATING ALGORITHM FOR ANALYSIS OF BROKEN IMAGES AND BURNED PELLET AND CORRELATION OF ITS PARAMETERS WITH THE PHYSICAL STRENGTH OF THE MATERIAL}

\section{Abstract}

In order to understand the impacts caused by crack formation and pellet deformation over the pellet physical quality, it was developed an algorithm that, through automatic image analysis, is able to measure the crack size, width and length, and to make the measurements of size and morphology of the fired pellet. Pellets produced with hydrated ore were analyzed (high goethite content into the mineralogical composition) with 2 different thermal profiles. The data obtained in the image analysis were correlated with the cold compression strength of the pellets and showed that the size of the cracks denotes notorious correlation with its physical quality. The measurement of the cracks formed as a consequence of the pellet deformation in the bed (named as resilience) shows the influence of the pressure into the fired pellet quality and the optimum point in which no impact will be detected. The size of thermal cracks also shows to be essential (even under not aggressive firing profiles, crack formation was observed). In summary, the crack width, length and size showed correlation with the pellet physical strength. Based on the outcome, the evaluation of cracks can help in the optimization of thermal profiles of pelletizing furnaces.

Keywords: Pellets; Cracks; Automatic image analysis.

1 Técnico em Metalurgia e Materiais, Técnico de Processos, Departamento de Engenharia de Processo, Samarco, Anchieta, ES, Brasil.

2 Técnico em Metalurgia e Materiais, Técnico Especialista, Departamento de Engenharia de Processo, Samarco Mineração S.A., Anchieta, ES, Brasil.

3 Técnico em Mineração, Laboratorista, Departamento de Engenharia de Processo, Samarco Mineração S.A., Anchieta, ES, Brasil.

4 Engenheiro Metalúrgico, Chefe de Equipe de Laboratório, Samarco Mineração S.A., Anchieta, ES, Brasil.

5 Msc Metalurgia e Materiais, Engenheiro Especialista, Gerência de Tecnologia e Ecoeficiência, Mineração S.A., ES, Brasil. 


\section{INTRODUÇÃO}

Pelotas com resistência mecânica adequada suportam melhor às solicitações de natureza física relacionadas às etapas de manuseio e transporte, além de serem menos susceptíveis aos efeitos de degradação, decorrente das mudanças de estrutura cristalina durante a redução. Uma adequada resistência física das pelotas queimadas é o objetivo principal de uma planta industrial e é frequentemente usada como parâmetro de controle do processo produtivo [1], ou seja, tem relação direta com a produtividade dos fornos de pelotização. Isso é particularmente importante para o contexto da Samarco, onde se emprega minérios hematíticos-goethíticos que impactam negativamente a relação resistência física-produtividade [2-4].

A resistência mecânica das pelotas é atribuída em grande parte à sinterização das partículas de minério e a formação de fases escorificadas durante o seu processo de fabricação, na etapa de queima [5]. Além dos fatores relacionados a sinterização, outros autores $[4,6]$, ainda mostraram que o tempo e temperatura adotados na etapa de secagem nos fornos de pelotização, influenciam fortemente o processo de endurecimento, causando um efeito na qualidade física representada pela resistência à compressão. Em seu estudo, Pereira [6] consideraram que a secagem era a etapa mais difícil de se tratar. Entre as conclusões do estudo, o tamanho da pelota mostrou-se muito importante, pois quanto maior o tamanho, mais lenta era a secagem.

Avaliando as propriedades físicas de pelotas de minério de ferro em diferentes perfis de temperatura de queima, Fonseca [7] observou uma tendência de a resistência à compressão se elevar quando um perfil térmico com menor inclinação na rampa de temperatura de endurecimento era empregado. Provavelmente o aumento da resistência à compressão a frio foi obtido devido ao maior percentual de pelotas sem trincas.

Em geral, o forno de grelha móvel para minérios hidratados como os da Samarco, Figura 1, apresentam 2 etapas de secagem: ascendente e descendente. Ou seja, o fluxo gasoso segue no sentido ascendente (de baixo para cima) e em seguida descendente (de cima para baixo) [8].

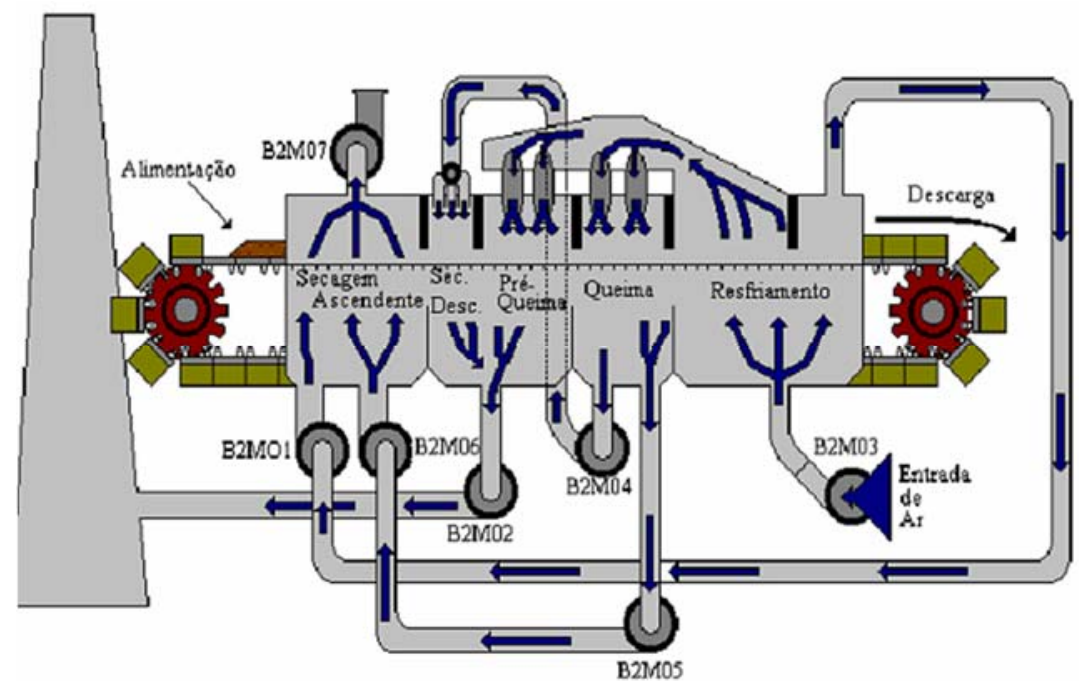

Figura 1. Fluxograma do forno de endurecimento do tipo grelha móvel Fonseca [7]

Buscando determinar as origens das trincas nas pelotas, Fonseca [4] interrompeu o processo de secagem ascendente, descendente e pré-queima. Verificou-se que as 
trincas de resiliência são resultantes de esforços de compressão das pelotas causadas pela superposição de uma sobre as outras no leito na etapa de secagem e também do excesso de água nas camadas superiores do leito durante a secagem ascendente. As trincas térmicas são resultantes do choque térmico nas pelotas na transição da etapa de secagem descendente para a etapa de pré-queima, que por sua vez é também uma consequência da deficiência na etapa de secagem. A Figura 2 mostra as trincas descritas no estudo.

Trincas térmicas

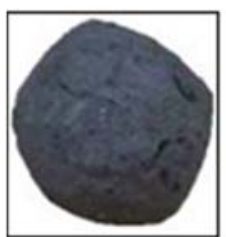

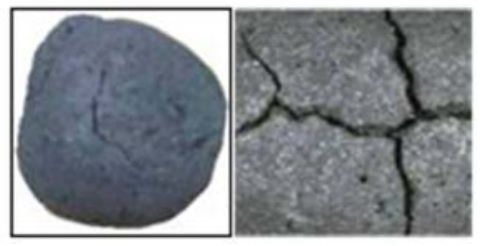

Figura 2. Tipos de trincas determinados por Fonseca, [4].
Trincas de resiliência
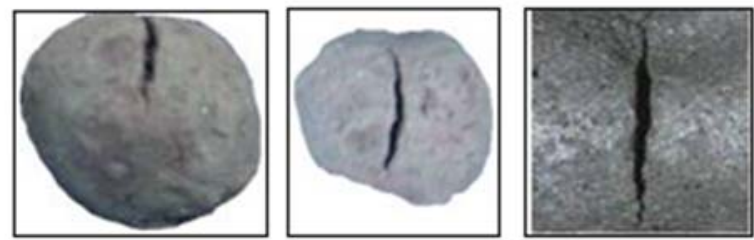

\section{MATERIAIS E MÉTODOS}

Utilizou-se, para a aquisição de imagens um equipamento desenvolvido na Samarco descrito por Simões [9] (Figura 3) que possibilita a visualização de detalhes na superfície das pelotas. $O$ analisador de imagens AxioVision, Zeiss, foi utilizado para elaboração do algoritmo para processamento das imagens, possibilitando o reconhecimento das características superficiais da pelota. A figura 3 mostra o equipamento utilizado para a captura e a imagem de uma pelota por ele adquirida.

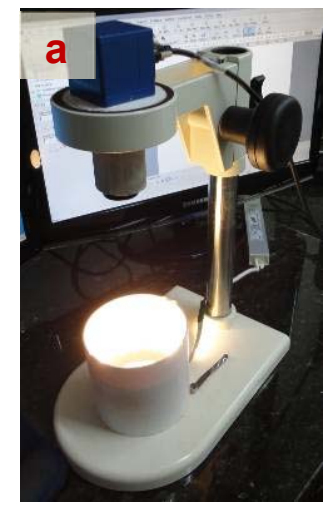

b

Figura 3. Equipamento de captura de imagens (a) e imagem de pelota (b).

Dois perfis térmicos foram utilizados para queima das pelotas denominados $\mathrm{A}$ e $\mathrm{B}$. $\mathrm{O}$ perfil $B$ é mais suave, com maior área de pré-queima e pós queima, além de menor zona de queima, bem como maiores pressões. Figura 4 mostra as diferenças nas zonas do forno. A resistência à compressão foi medida conforme norma ISO 4700:2007 [10].

Foram separadas pelotas com trincas térmicas, trincas de resiliência e sem trinca, para serem medidas no algoritmo desenvolvido. Esses três tipos de pelotas foram submetidos à análise de compressão e o resultado foi correlacionado com os parâmetros obtidos no algoritmo de análise de trincas. 
Perfil A

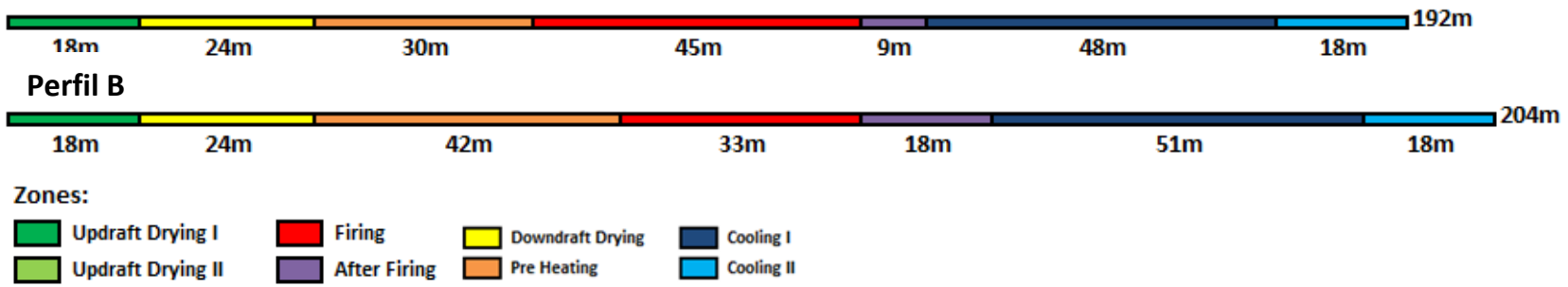

Figura 4. Dimensões utilizadas para determinação do perfil.

\section{RESULTADOS E DISCUSSÃO}

\subsection{Desenvolvimento do Algoritmo}

O algoritmo objetivou a identificação dos tipos de trincas, através da determinação do comprimento e largura da trinca, bem como a medição da morfologia da pelota queimada. Informações como comprimento e largura da trinca auxiliam na identificação do tipo de trinca, tendo em vista que as térmicas possuem menor largura. A morfologia da pelota é importante, pois as trincas de resiliência têm por característica surgir do amassamento da pelota na etapa de secagem. Assim, faz-se necessário medir o quanto a pelota difere de uma esfera (círculo no caso da análise de imagens que é bidimensional). Na Figura 5 são apresentadas imagens provenientes de pelota com trinca térmica (a) e de resiliência (b), respectivamente, analisadas no algoritmo.
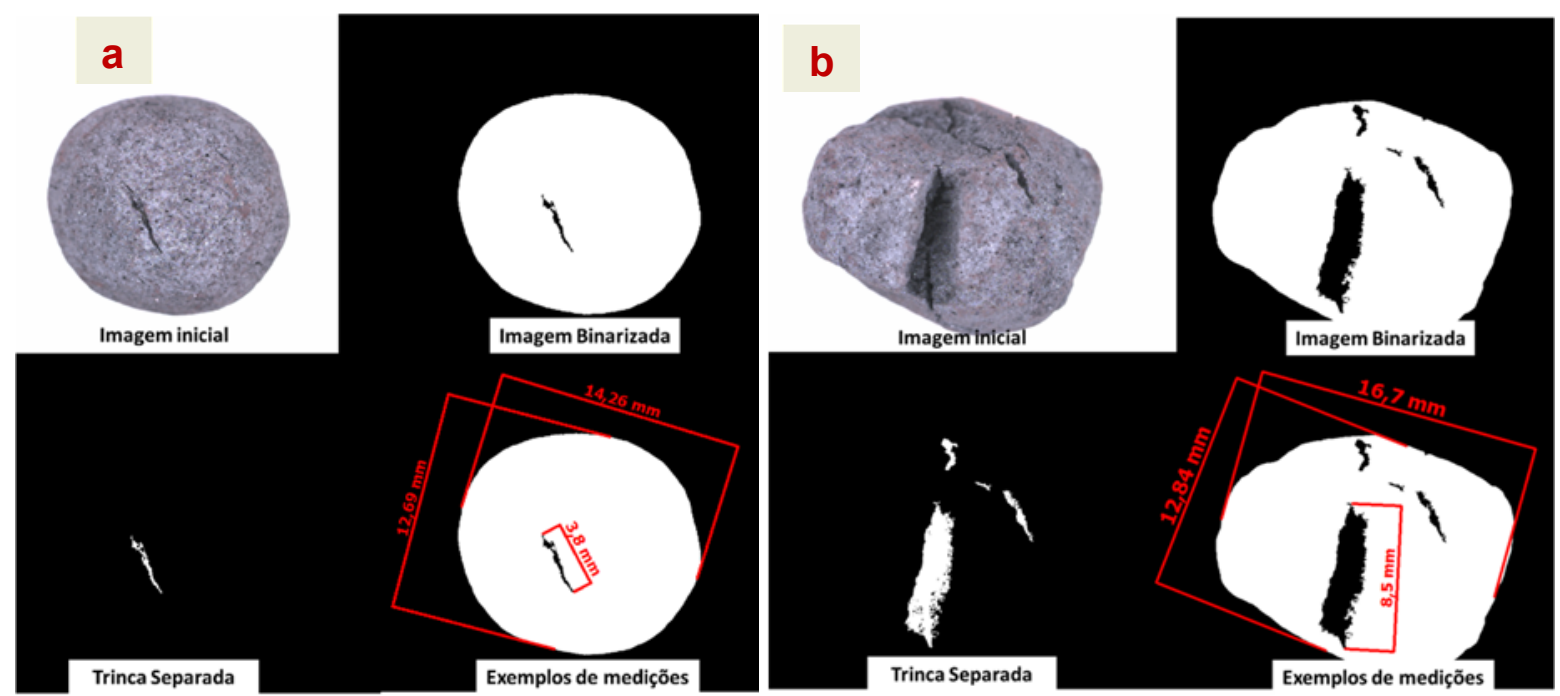

Figura 5. Imagens de pelota com trinca térmica (a) e trinca de resiliência (b), analisadas pelo algoritmo.

A Tabela 1 mostra os parâmetros medidos pelo algoritmo desenvolvido, tanto para a pelota queimada quanto para as trincas.

Tabela 1. Parâmetros medidos pelo algoritmo desenvolvido

\begin{tabular}{|c|c|c|c|c|c|c|c|c|c|}
\hline $\begin{array}{l}\text { Parâmetros de } \\
\text { mediçãoda pelota } \\
\text { queimada }\end{array}$ & $\begin{array}{l}\text { Diâmetro } \\
\text { Médio da } \\
\text { pelota }\end{array}$ & $\begin{array}{c}\text { Circularidade } \\
\text { da pelota }\end{array}$ & $\begin{array}{l}\text { Razão } \\
\text { Comprimento } \\
\text { / Largura }\end{array}$ & Raio pelota & $\begin{array}{c}\text { Área } \\
\text { Preenchida } \\
\text { Pelota }\end{array}$ & & & & \\
\hline $\begin{array}{l}\text { Parâmetros de } \\
\text { mediçãoda trinca }\end{array}$ & Comprimento & Largura & Diâmetro & Circularidade & $\begin{array}{l}\text { Razão } \\
\text { Comprimento } \\
\text { / Largura }\end{array}$ & Raio & $\begin{array}{c}\text { Área } \\
\text { Preenchida }\end{array}$ & Área & Perímetro \\
\hline
\end{tabular}


A Figura 6 mostra imagens lidas no algoritimo de pelota com trinca térmica ramificada, sua imagem binarizada e da trinca ( $a$, b e c). Mostra também imagem de pelota sem trinca (d), sem trinca binarizada (e) e a imagem da região da trinca (f).
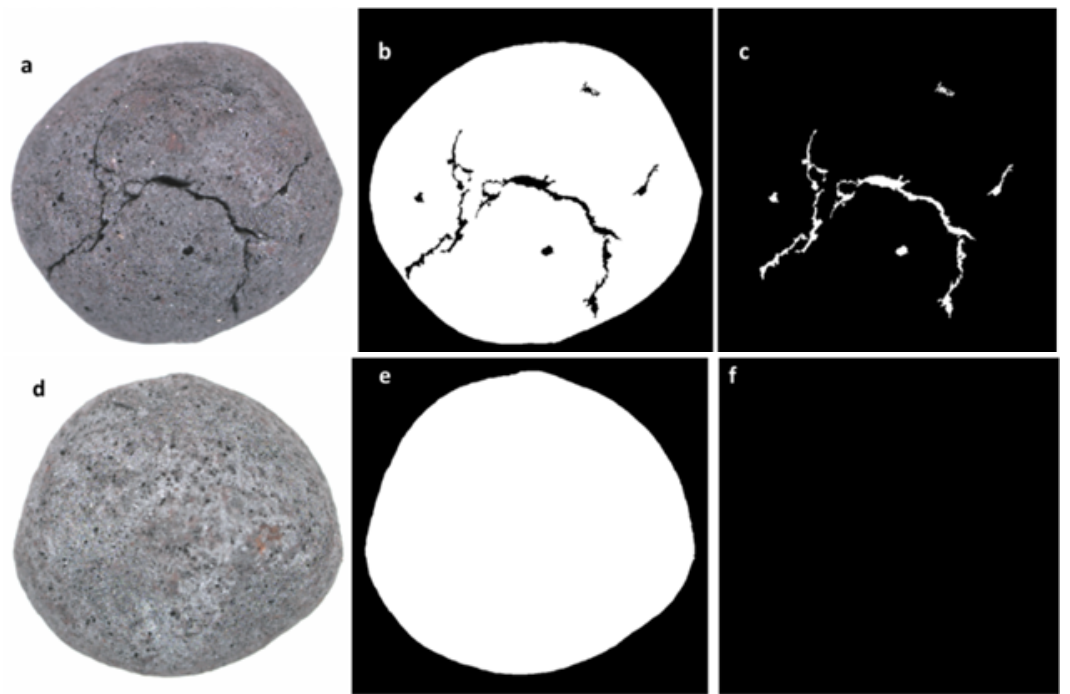

Figura 6. Trinca térmica ramificada, binarizada e trinca (a), (b) e (c), respectivamente. Pelota sem trinca, binarizada, imagem mostrando que não foi identificada trinca (d), (e) e (f), respectivamente.

\subsection{Qualidade Física}

A Tabela 2 mostra os resultados da caracterização do pellet feed, com alto teor de ppc e da pelota crua.

Tabela 2. Caracterização física do pellet feed e da pelota crua

\begin{tabular}{|c|c|c|c|}
\hline \multicolumn{2}{|c|}{ Análise Física do PF } & \multicolumn{2}{|c|}{ Análise Física da Pelota Crua } \\
\hline Umidade (\%) & 11,05 & Umidade (\%) & 10,38 \\
\hline $\mathrm{SE} \mathrm{cm} 2 / \mathrm{g}$ & 2123 & Comp.U. & 1671 \\
\hline$-325 \#$ & 91,5 & Comp.S. & 5148 \\
\hline PPC (\%) & 3,95 & Resiliência & 10,2 \\
\hline
\end{tabular}

A Tabela 3 mostra os resultados físicos da pelota queimada. Nota-se que o não houve grandes alterações no valor de tamboramento. A resistência à compressão, por outro lado, denota que o perfil "B" apresenta melhore resultados.

Tabela 3. Caracterização física da pelota queimada

\begin{tabular}{ccc} 
Tamboramento(\%) & Perfil A & Perfil B \\
\hline TB+6,3 & 94,3 & 94,1 \\
\hline AB-0,5 & 5,1 & 5,0 \\
\hline \hline $\begin{array}{c}\text { Resistência à Compressão } \\
\text { (Kgf/Pel) }\end{array}$ & Perfil A & Perfil B \\
\hline CCS & 296 & 355 \\
\hline
\end{tabular}




\subsection{Qualidade Física X Trincas}

Após a separação visual dos tipos de trinca, as pelotas foram submetidas a ensaio de resistência à compressão e verificou-se diferentes tendências conforme o perfil utilizado. A Figura 7 mostra os resultados da compressão média por tipo de trinca e sem trincas em cada perfil. Nota-se que o perfil "B" apresenta melhores resultados de compressão, independente do tipo de trinca. Fica bastante clara a diminuição do valor de compressão nas pelotas com trinca térmica do perfil "A" (238Kgf/Pel). As pelotas sem trinca possuem maior resistência nos dois perfis.

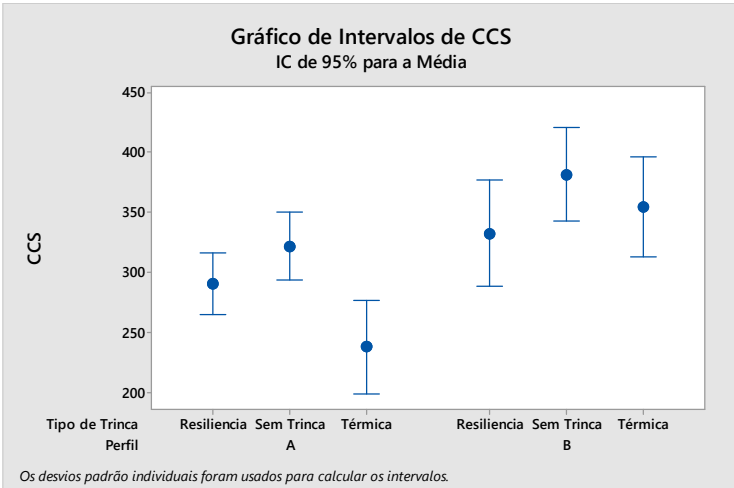

Figura 7. Resistência à compressão média por tipo de trinca.

A distribuição dos valores de compressão por pelota, mostrados na Figura 8, denotam que aproximadamente $50 \%$ das pelotas com trincas térmicas do perfil "A" apresentam resistência menor que $200 \mathrm{kgf}$.

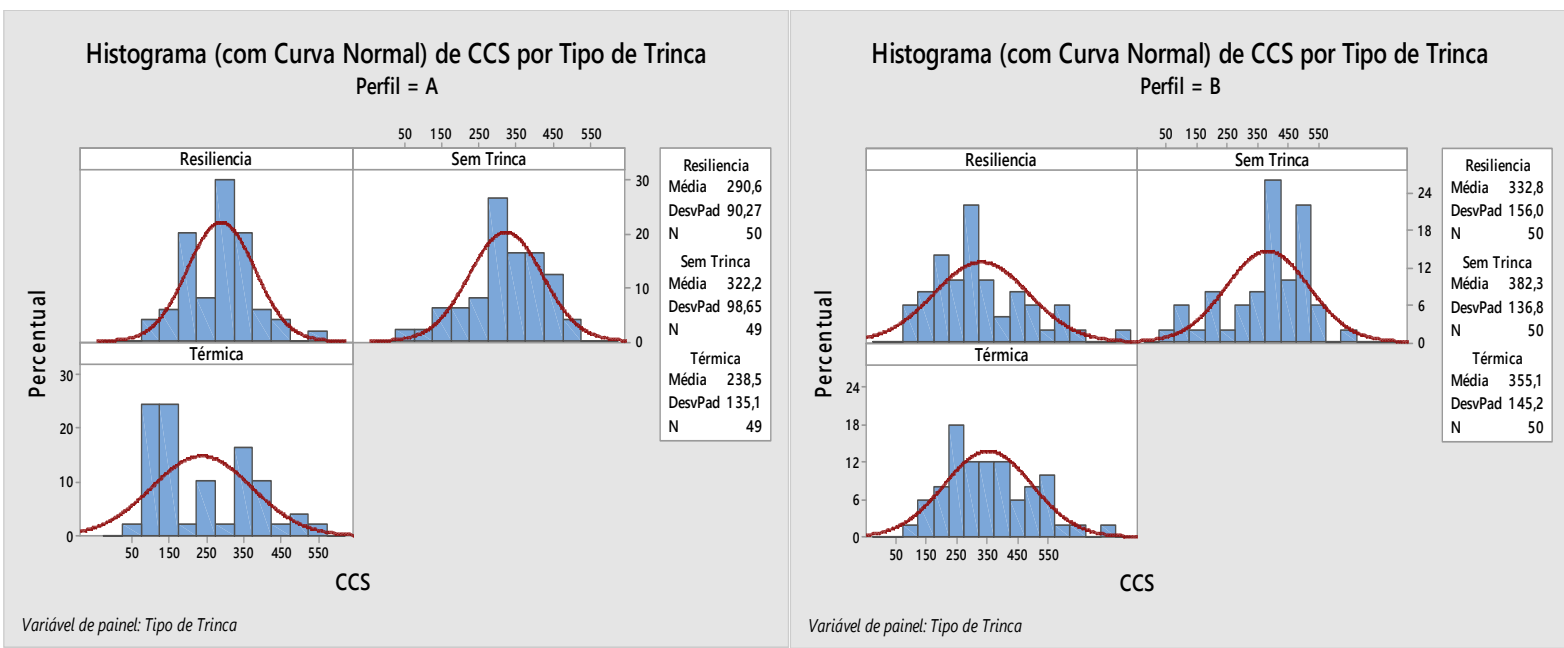

Figura 8. Distribuição da resistência à compressão por tipo de trinca.

O gráfico da Figura 9(a) mostra o tamanho máximo da trinca (denominado " $D$ "), isto é, o comprimento da mesma. Nota-se que as trincas de resiliência tanto do perfil "A" quanto do "B" possuem tamanho mais elevado, entre $6 \mathrm{~mm}$ e $7 \mathrm{~mm}$. No entanto, era esperado que as trincas térmicas apresentassem menor tamanho, mas nota-se que no perfil " $A$ " as trincas térmicas também são de elevado tamanho. Levando-se em conta que o tamanho máximo das trincas térmicas do perfil " $\mathrm{A}$ " é consideravelmente maior que no perfil "B" pode-se concluir que tais trincas são ramificadas, isto é, estendem-se por grande parte da superfície da pelota, resultando em elevado tamanho. 
O gráfico da figura 9 (b) mostra uma razão entre o comprimento máximo da trinca e a área da trinca (denominada "A"), indicando a abertura da trinca (quanto menor a razão, maior a abertura da trinca). Pode-se observar que as trincas de resiliência tanto do perfil "A" quanto "B" apresentam trincas com largura aproximada, enquanto as trincas térmicas do perfil " $A$ " diferem-se das do perfil "B" por apresentarem maior largura.

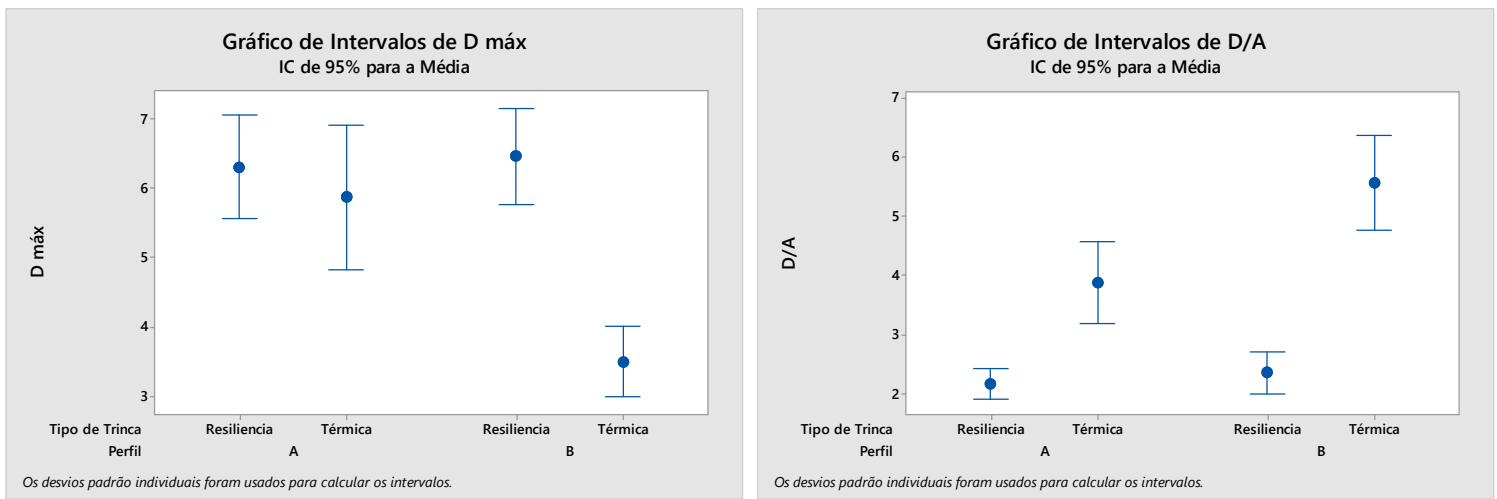

Figura 9. Gráficos de diâmetro máximo da trinca (a) e razão comprimento / área da trinca.

Depois de identificado que as pelotas com trincas térmicas ramificadas apresentam resistência à compressão menor que as pelotas de resiliência, decidiu-se embutir pelotas inteiras com trincas de resiliência, térmica e térmica ramificada, além de pelotas sem trincas e posteriormente cortá-las ao meio em uma cut-off. A Figura 10 mostra as imagens obtidas após o corte, onde se pode notar que a pelota trinca térmica ramificada apresentou estrutura interna muito fragilizada, com trincas em todas as regiões da pelota, deixando-a quebradiça, o que pode justificar a tendência de menor resistência à compressão deste tipo de pelota. Na pelota com trinca térmica pequena em sua superfície, foram encontradas trincas concêntricas em seu interior, diferindo-se da estrutura encontrada nas trinca ramificada. A pelota com trinca de resiliência mostrou também trincas em seu interior, porém não passam pelo seu centro. A pelota sem trinca na superfície não apresentou trinca relevante em seu interior, o que justifica a maior resistência à compressão dessas pelotas.

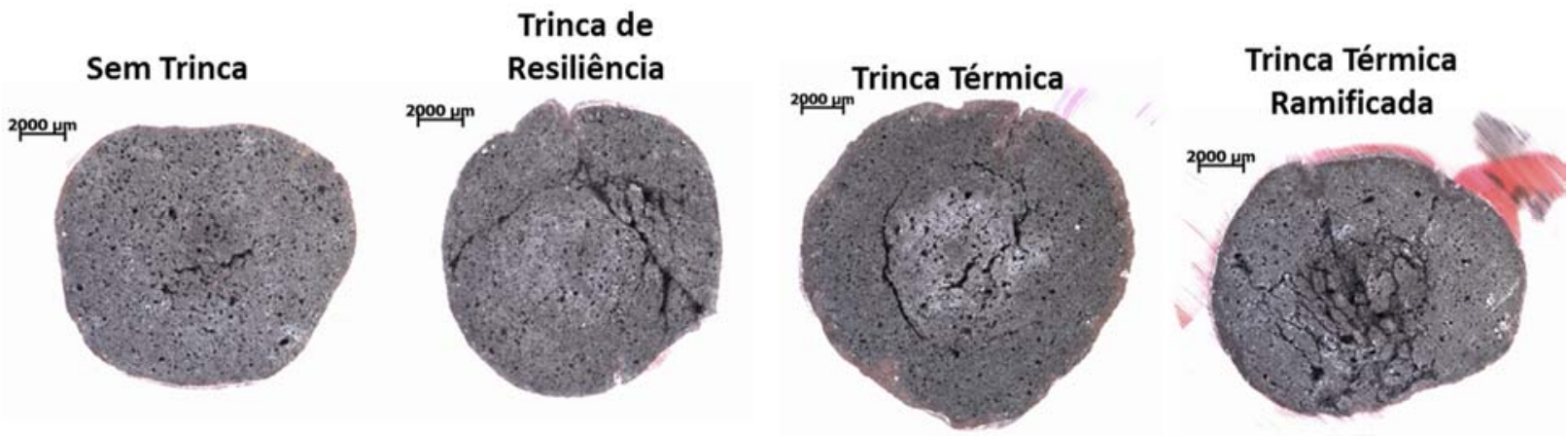

Figura 10. Corte de pelotas que apresentavam trincas em sua superfície.

\subsection{Qualidade Física X Morfologia da Pelota}

Avaliando-se o tamanho da pelota, medido por análise automática de imagens, notase que as menores compressões estão nas pelotas de maior diâmetro, figura 11 (a). Em termos de morfologia da pelota, a Figura 11 (b) mostra que as pelotas com trinca de resiliência apresentam maior amassamento, isto é, quanto menor o valor da razão C/L (Comprimento/Largura) maior é o achatamento da pelota. Ressalta-se que 
mesmo estando amassadas as trincas de resiliência do perfil " $A$ " não acarretaram em tão grande perda de resistência quanto as pelotas com trincas térmicas. No perfil "B" este tipo de trinca trouxe maior prejuízo à resistência da pelota, porém em patamares menores que o de trincas térmicas do outro perfil.
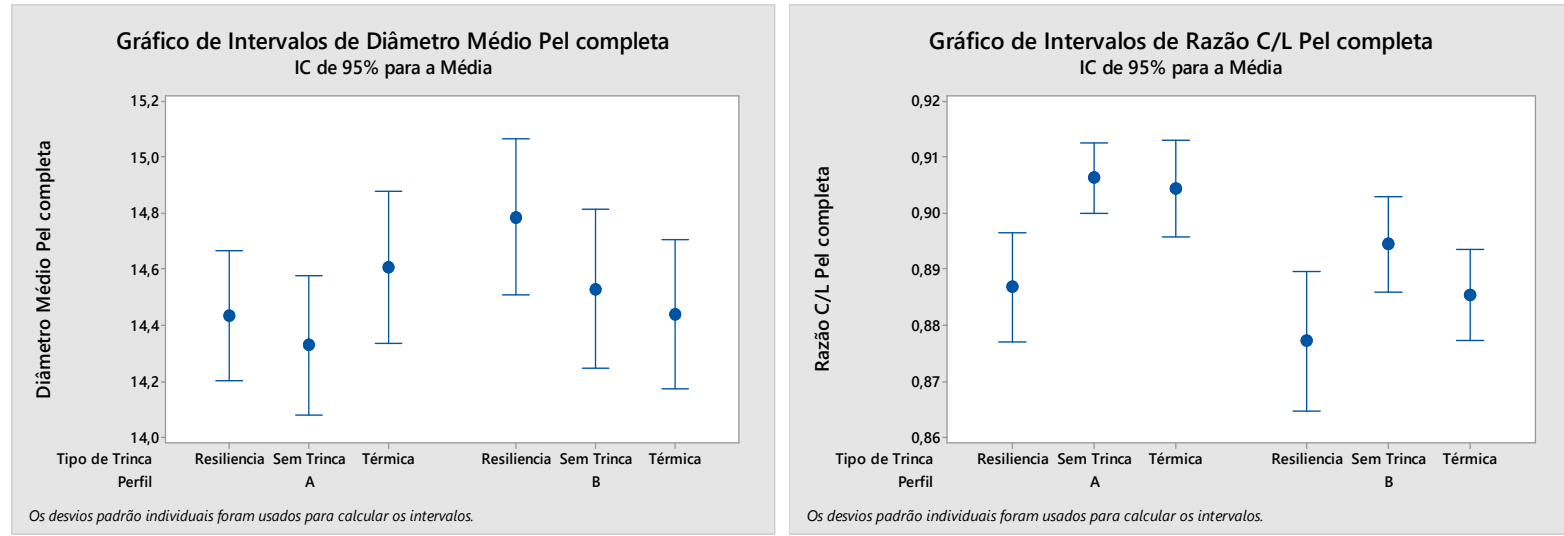

Figura 11. Gráficos de diâmetro médio da pelota e razão comprimento x largura da pelota.

\section{CONCLUSÃO}

O algoritmo desenvolvido mostrou-se eficiente na detecção das trincas presentes na pelota, analisando seu tamanho e proporções, bem como na avaliação da morfologia da pelota, indicando deformações e tamanho;

O perfil "B" apresentou melhor resistência física independente do tipo de trinca na pelota;

Houve diferentes comportamentos quanto à resistência à compressão para os dois perfis térmicos analisados. Para o perfil "A", as trincas térmicas mostraram-se mais prejudiciais à qualidade da pelota, sendo que ao menos $50 \%$ de suas pelotas apresentavam compressão menor que 200Kgf;

A análise morfológica da trinca mostrou que a queda no valor de compressão das pelotas do perfil "A" deveu-se ao maior tamanho de tais trincas, bem como à suas ramificações. Imagens de pelotas embutidas inteiras e posteriormente cortadas ao meio denotaram que as trincas térmicas ramificadas estendiam-se por toda a área da pelota e que trincas térmicas normais (menores), mesmo que externamente pequenas, apresentavam extensões circuncêntricas.

A análise do tamanho da pelota evidenciou que as pelotas com perdas mais significativas de compressão (com trincas térmicas no perfil "A" e trinca de resiliência no perfil "B") eram, em média, maiores que as demais;

Em termos de amassamento, as pelotas com trincas de resiliência apresentam maior deformação que as demais, como esperado.

\section{REFERÊNCIAS}

1 Batterham RJ, Modeling the Development of Strength in Pellets, Metallurgical Transactions B, Londres, Vol 17B, 1986.

2 Toríbio NM, Estudo das características intrínsecas dos concentrados do minério de ferro do Complexo Alegria - 101 páginas. Dissertação de Mestrado, REDEMAT - Ouro Preto, 2001.

3 SÁ KG - Estudo da influência da mineralogia dos tipos de minério da Samarco Mineração sobre a resistência a compressão de pelotas para processos de redução direta - 86 páginas. Dissertação de Mestrado, REDEMAT - Ouro Preto, 2003. 
4 Fonseca MC - Influência da Distribuição Granulométrica do Pellet Feed no Processo de Aglomeração e na Qualidade da Pelota de Minério de Ferro para Redução Direta 126 páginas. Dissertação de Mestrado, REDEMAT - Ouro Preto, 2004.

5 Fonseca VO - Envelhecimento de pelotas de minério de ferro com diferentes basicidades e teores de $\mathrm{MgO}$ - 253 páginas. Dissertação de Mestrado, REDEMAT Ouro Preto, 2003.

6 Pereira ROS, Seshadri $\mathrm{V}$ - Secagem de pelotas de minério de ferro - Metalurgia ABM, V. 41, n. 328, p.141-144, 1985.

7 Fonseca MC, Nunes SF - Relatório interno - Desagregação da carga circulante do pelotamento através do roller press - Samarco Mineração - 2003.

8 Athayde, M - Modelamento Fluidodinâmico da Zona de Queima de Fornos de Grelha Móvel para Pelotização de Minério de Ferro - 101 páginas. Dissertação de Mestrado, UFMG, 2013.

9 Simões HO, Bailon AMG, Meschiatti A, Passigatti VP, Doellinger TM - Desenvolvimento de uma metodologia para determinação do percentual de coating em pelotas queimadas via análise automática de imagens. Contribuição técnica ao $43^{\circ}$ Seminário de Redução de Minério de Ferro e Matérias-primas, $14^{\circ}$ Simpósio Brasileiro de Minério de Ferro e $1^{\circ}$ Simpósio Brasileiro de Aglomeração de Minério de Ferro, 1 a 4 de setembro de 2013, Belo Horizonte, MG, Brasil

10 ISO 4700:2007 - Iron ore pellets for blast furnace and direct reduction feedstocks Determination of the crushing strength. 